\title{
Interdisciplinary decision support model for grid-bound heat supply systems in urban areas
}

\author{
Susanna Erker ${ }^{1 *}$ (D), Peter Lichtenwoehrer ${ }^{1}$, Franz Zach $^{2}$ and Gernot Stoeglehner ${ }^{1}$
}

\begin{abstract}
Background: In the past two centuries, energy consumption per capita has significantly increased. At the same time the fundamentals of energy provision have continuously developed towards fossil energy sources. This extended use of finite, unequally distributed and emission-intensive energy sources poses a challenge to both the energy, the climate and therefore the socio-ecological systems. Consequently, solutions are needed to reduce the fossil energy demand while fulfilling our daily energy services. District heating systems powered by renewable energy can contribute to this societal mission.

Methods: This paper presents the co called Eco.District.Heat-kit, a novel planning model supporting future decision-making processes regarding grid-bound heating. The interdisciplinary approach assesses the feasibility of district heating systems at different locations from a qualitative and quantitative perspective. Given the lack of quick and simple planning tools in this field, the Eco.District.Heat-kit provides a time-efficient pre-evaluation on the basis of widely available input data.
\end{abstract}

Results: The decision support model rates district heating networks regarding the thematic areas of (1) integrated spatial and energy planning (2) costs, (3) resources, and (4) environment and climate. In addition, it involves a longterm planning horizon by including spatial development and climate scenarios until 2050. Finally, the Eco.District. Heat-kit identifies parameters both positively and negatively influencing the overall rating. This enables end-users to sort out non-optimal configurations before entering a more detailed planning stage.

Conclusions: Due to the straightforward methodological approach and the focus on basic parameters of district heating system planning, the Eco.District.Heat-kit supports energy suppliers, urban-planners and decision-makers at the beginning of planning processes. In order to increase both transparency and applicability of the model, its functionality and input parameters are disclosed within this paper, enabling the recreation and adaptation towards user-specific needs and local situations.

Keywords: Energy supply, District heating, Preliminary assessment, Cross-thematic evaluation, Urban planning, Integrated spatial and energy planning, Decision support model, Eco.District.Heat-kit

\footnotetext{
* Correspondence: susanna.erker@boku.ac.at

${ }^{1}$ Institute of Spatial Planning, Environmental Planning and Land

Rearrangement, University of Natural Resources and Life Sciences, Vienna,

Peter-Jordan-Strasse 82, 1190 Vienna, Austria

Full list of author information is available at the end of the article
}

(c) The Author(s). 2019 Open Access This article is distributed under the terms of the Creative Commons Attribution 4.0 International License (http://creativecommons.org/licenses/by/4.0/), which permits unrestricted use, distribution, and reproduction in any medium, provided you give appropriate credit to the original author(s) and the source, provide a link to the Creative Commons license, and indicate if changes were made. 


\section{Background}

\section{Urbanization and the energy system}

The world's population has increased significantly during the last decades, triggered by improved health care systems, the industrial production of nitrogen fertilizers and the Green Revolution, leading to rising agricultural yields [1]. Besides the initiated hyper exponential growth of population within the last 2000 years and substantial growth rates within the last century [2], its spatial distribution has also shifted. Since the beginning of this millennium, more people are living in urban than in rural areas for the first time in history. This so called "urbanization" leads to the spreading of urban lifestyles especially effective in states with expanding industries and/or low potentials for employment in rural areas [3, 4]. The Population Division of the United Nations Department of Economic and Social Affairs predicts further global population growth from now 7.5 to 9.7 billion until 2050. By then, 6.4 billion people (about $65 \%$ of the total population) may live in cities [5]. Figure 1 illustrates both, the trend of growth and urbanization since 1950 and gives an outlook on how urban and rural regions may develop in the future.

Along with population growth and the physical, functional and social expansion of urban life, another global trend has been noticed over the last decades, regarding the use of energy. Before the industrial revolution, the energy consumption reached 20 GJ per capita and year, translating to approximately $20 \mathrm{EJ}$ of global energy use in 1800 [6]. Due to economic growth, industrialization and the multiplying population $[1,7,8]$, the global primary energy use has grown to about 80 GJ per capita or
$600 \mathrm{EJ}$ in total in 2017 [9, 10]. Furthermore, not only the extent but also the areas of consumption have changed. Figure 2 illustrates the over-proportional consumption of industrialized countries per capita and the increasing energy demand and population in developing regions within the last years. Considering urban growth rates in developing countries, a strong increase in energy consumption can be assumed analogously in these areas.

However, not only the total amount per capita but also the composition of energy consumption has radically changed, as shown in Fig. 3. Whereas biomass was the dominant source of energy in the early 1800s, since the middle of the twentieth century traditional biofuels were increasingly replaced by fossil energy sources such as coal, oil and gas.

Estimating future developments regarding the energy system, today's global primary energy consumption will increase by another 30\% till 2040 [11], enabling mechanical work, lighting, heating and cooling for society. However, this trend causes far-reaching challenges. Since the majority of our current energy use is based on fossil and thus emission-intensive, unequally distributed and finite energy sources, our energy consumption exceeds the limits of global carrying capacity. On the one hand, this refers to the currently unsustainable and depleting use of limited resources such as oil, coal and gas and, on the other hand, to global warming, which is largely caused by the use of fossil fuels [12]. Therefore, the already high, still rising and fossil based energy consumption appears to be one of the grand challenges of our time, also reflected in national and international strategies aiming

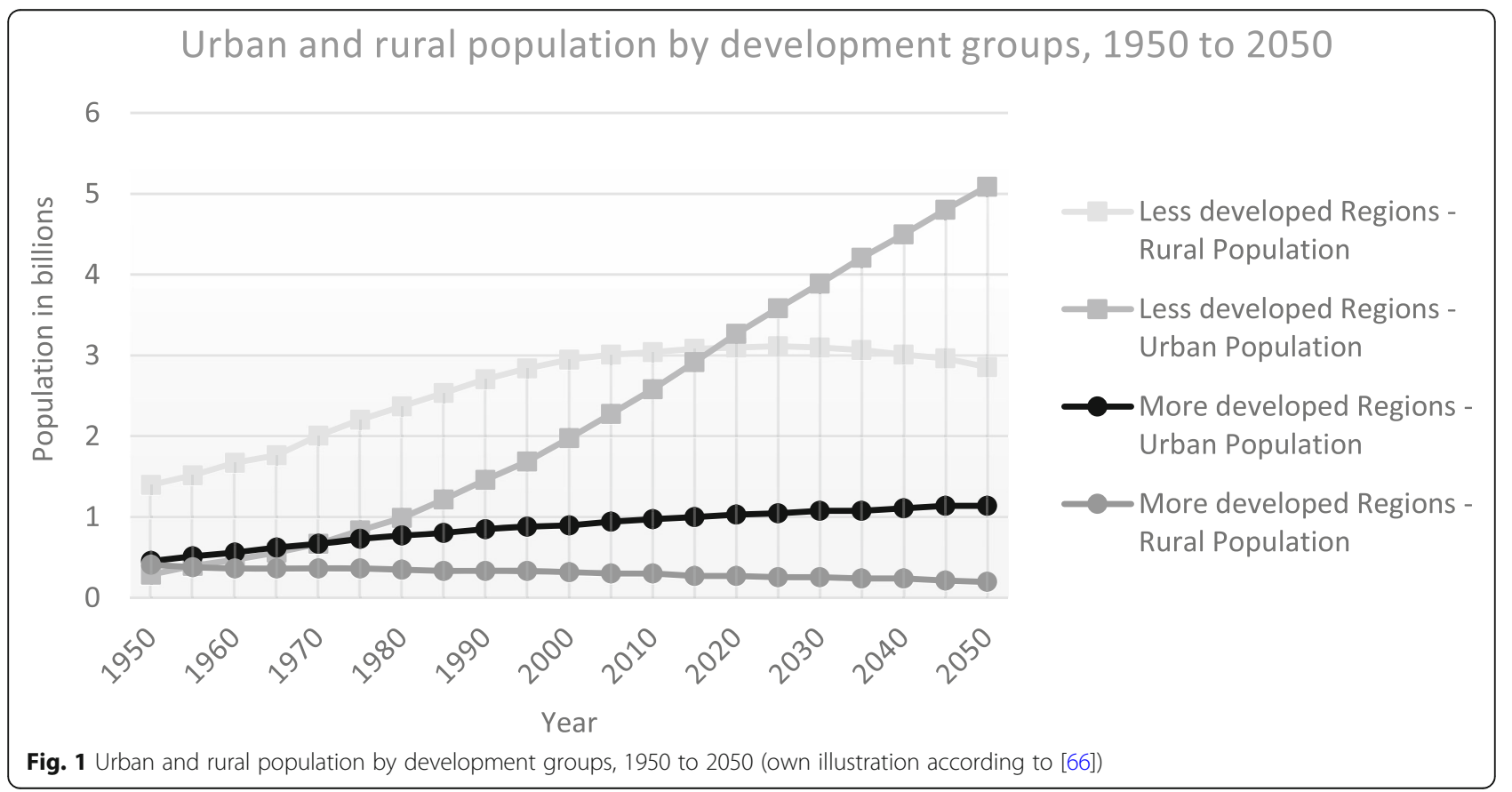




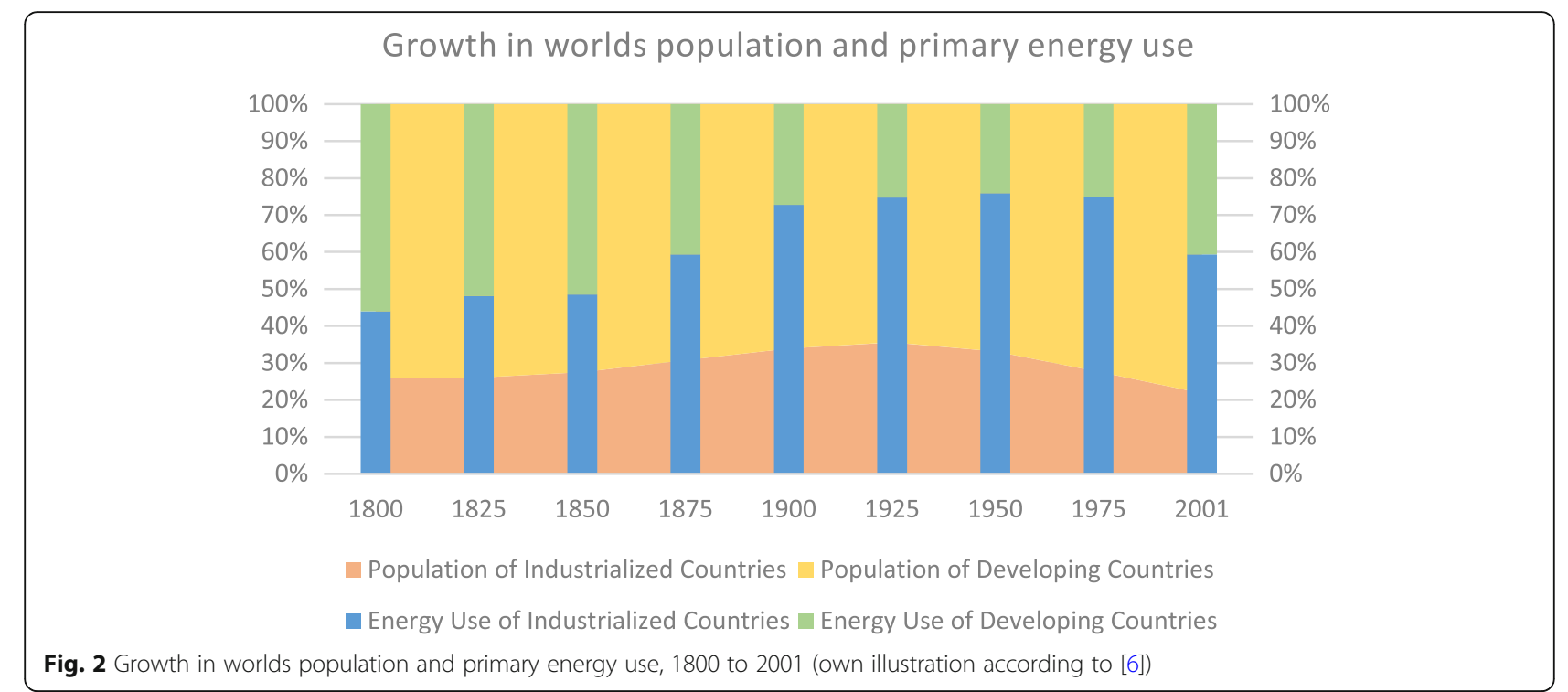

to protect our climate by transforming the energy system [13-16]. Concluding from documents such as the Kyoto Protocol(s) or the Paris Agreement, 1) the reduction of energy consumption, 2) the increase in energy efficiency and 3) the expansion of renewable energy sources are "key-objectives". Based on these three goals, measures have to be determined to cut negative trends in global energy consumption, even if the demand for affordable, acceptable and accessible energy services of the steadily growing world population will presumably increase.
For an effective implementation of measures in line with international strategies on energy reduction, efficiency and decarbonization, it is mandatory to identify those key areas and aspects enabling optimal transformation processes. Here, the constantly increasing urbanization processes offer a new scope of action. Since urban areas are characterized by

- a diverse mix and high density of consumer groups (e.g. the mix of functions such as housing, industry, retail and trade, services and mobility),

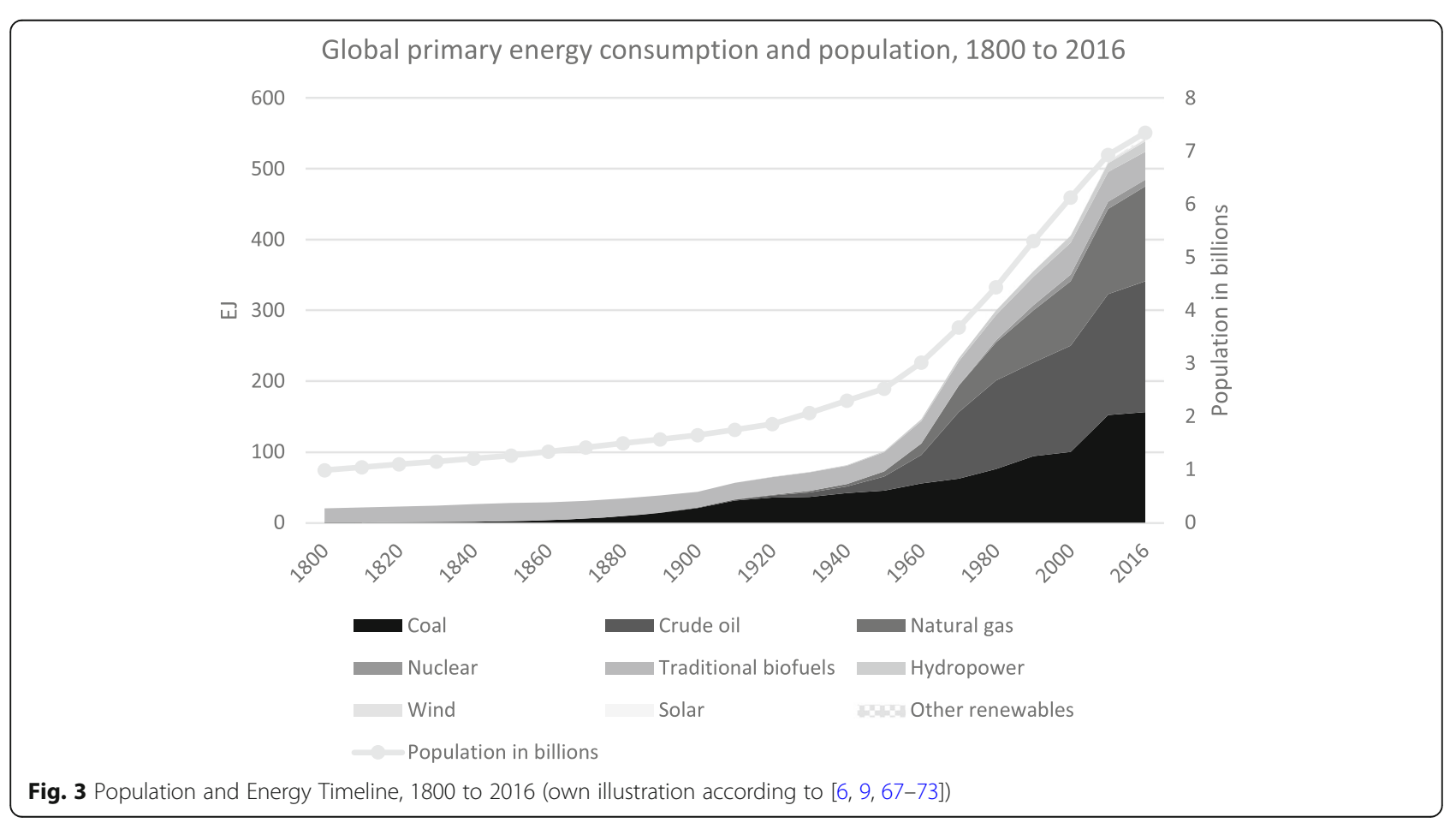


- a variety and high density of social and technical infrastructure (e.g. supply and disposal, communication, transport infrastructure, financial system, education system, health system, cultural institutions, public safety, sport and leisure),

- a broad spectrum of energy uses (e.g. heating, cooling, lighting, mechanical work, electricity)

- and a mixture of energy services (e.g. hot water preparation, space heating, food preparation, supply and disposal, production, information, transportation)

they accumulate high energy demands per area. Therefore, it is not surprising that $2 / 3$ of the world's primary energy needs and $70 \%$ of total carbon emissions originate from urban areas [17]. Besides these energy-demanding effects, the multi-layered distribution of energy dependent uses and functions on scarce space compensates temporal fluctuations in supply and demand [18]. Accordingly, measures implemented in urban areas can be particularly effective.

In order to explain this effect more closely, the study at hand is dedicated to the evaluation of potential transformation measures within urban energy supply systems while keeping energy reduction, efficiency and decarbonization strategies in mind. Hereby, our study depicts one central aspect of the urban energy system by focusing on heat supply.

\section{Heat supply}

On a global level, energy used for heating accounts for $1 / 3$ of primary and $1 / 2$ of global final energy consump- tion. Three quarters of the total primary energy used for heating is based on fossil fuels, while about $55 \%$ of this fossil fuel demand can be linked to industry and $40 \%$ to buildings. Overall, the building sector divided into residential and commercial buildings accounts for the largest amount of consumed heating energy, mostly used for space heating, but also hot water preparation and cooking [19]. Noteworthy, these three forms seldom require more than $100^{\circ} \mathrm{C}$, in contrast to process heat requirements within the industry sector [20].

Referring to the European level, the residential building sector also has priority when it comes to efficient and sustainable use of energy. With more than 3000 heating degree days per year, heating is prerequisite for a high level of living comfort within colder climates in Central and Northern Europe [21, 22]. At the same time, almost $75 \%$ of heating is fueled with fossil energy, while natural gas being the dominant fuel for households and industry nowadays [23]. Figure 4 illustrates both the estimated proportions of heat used in residential and service sector buildings on global and European level with respect to used energy sources according to [24]. Comparably more natural gas is used on the European level, while significantly higher shares of combustible renewables are used on the global level. Around 13\% of the heat is supplied by district heating $(\mathrm{DH})$ in the European Union, whereas only $8 \%$ worldwide.

The question remains open, how these consumption patterns can be changed in order to improve overall thermal-energy performance and, therefore, inhibit global warming, safeguarding the environment and creating resilient energy systems. On the one hand, the answer is

\section{Energy sources for heating on global and European level}

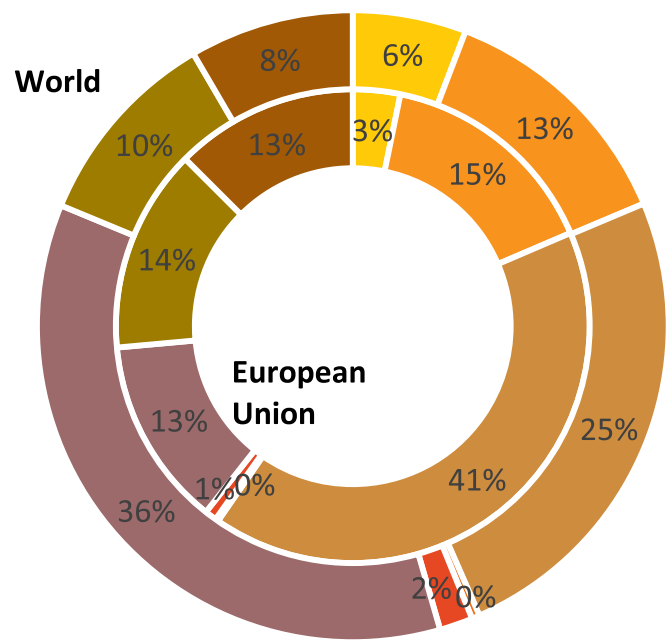

- Coal and Coal Products

- Petroleum Products

- Natural Gas

- Geothermal

- Solar/Wind/Other

- Combustible Renewables

- Electricity

- Heat

Fig. 4 Estimated proportions of different forms of heat used in residential and service sector buildings; "Heat" denotes commercial heat deliveries in IEA energy balances, while end-user categories are excluded (own illustration according to [24]) 
seen in a reduced heating demand, e.g. by refurbishing the existing building stock. On the other hand, implementing efficient forms of renewable energy utilization and implementing building-integrated renewable energy supply systems at the urban level will play a decisive role [25]. By promoting state of the art technologies of heat supply, decarbonization should be supported. Here, DH can be seen as one of the key technologies in urban areas.

\section{District heating}

DH has been used since the late nineteenth century and is experiencing an upswing ever since [26]. One reason is the possibility to use either one or more energy source(s) such as natural gas, biogas, wood chips and wood pellets for heat generation. DH is not only able to generate heat from different energy sources but also allows the use of otherwise unusable waste, sewage sludge or waste heat from sewage or industry $[19,26]$. Due to the central use of large, automatically operated heat generators with fine dust separators, pollution can be reduced compared to individual combustion technologies. Another reason for the increased usage of DH might be the "recovered" room within buildings linked to the district heating network (DHN), since the room requirements for central heating systems or boilers are eliminated. Furthermore, there is no need to deliver or store energy sources at home as well as to deal with on-site maintenance [27]. At the same time, heat networks must be seen as isolated solutions, quite in contrast to the widely connected gas and electricity grids. Due to heat distribution losses, the benefits of DH do not automatically justify large, regional or national installations [28].
Looking at the European level, especially countries with above-average climate-related demand for heating focused on the expansion of $\mathrm{DH}$ in the past [21, 22]. As shown in Fig. 5, about 50\% of the total district heating sales in the European Union take place in Poland, Germany, Sweden, and Finland. Considering the average use across all European member states, DH mainly supplies the residential sector (45\%), followed by the tertiary sector $(24 \%)$ and the industry (11\%). The highest shares of population served by DHNs per member state can be found in Scandinavian and Baltic countries, followed by Central and Eastern Europe. DH gain little importance in Southern Europe [29].

Besides the country-specific expansion and sector-dependent usage of this technology, the energy sources for DH can also be described as heterogeneous. In Eastern Europe, fossil energy such as coal and gas almost completely cover the energy supply for DH. In Sweden, Austria, and Estonia, Biomass represents the central energy input. Iceland is characterized by a high amount of geothermal energy, covering $97 \%$ of energy inputs for DH. Other forms of energy such as solar thermal play a subordinate role at European level. In conclusion, up to $3 /{ }_{4}$ of $\mathrm{DH}$ is based on fossil energy in the European Union [24, 29, 30]. Due to climate protection reasons, renewable energy will have to increase in future district heating systems (DHS).

The long-term feasibility of this technology highly depends on national and international energy policies $[24,31]$ :

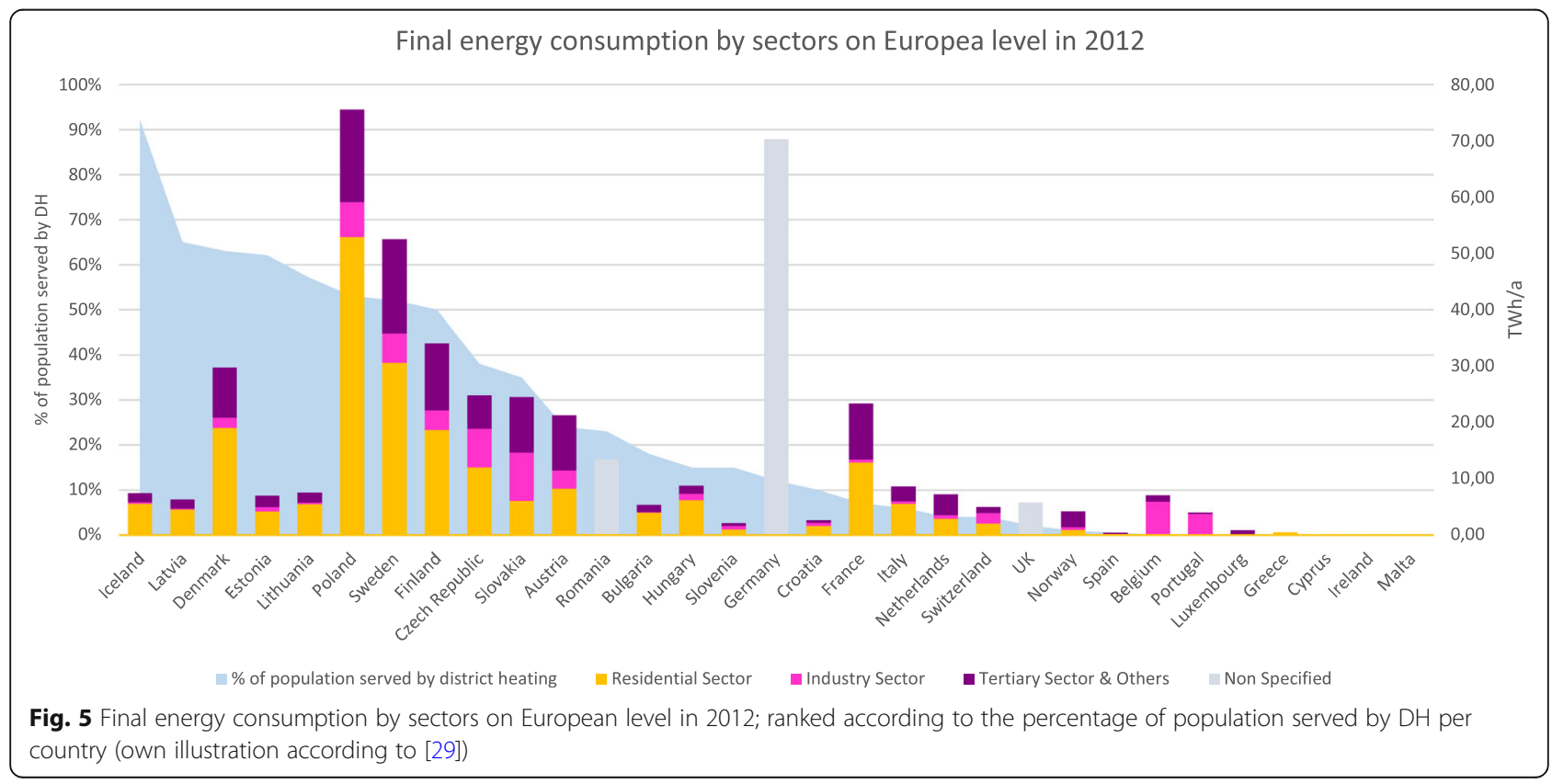


- by building, owning, and managing DHSs, local authorities are seen as one central driving force behind DH [32]

- mandatory connections to DHS in newly built and / or redeveloped buildings and /or districts support the development of DH $[29,32]$

- the desire of being independent from fossil energy imports promotes this technology [32, 33]

- policies concerning low carbon energy by e.g. promoting bioenergy in close consultation with the agricultural sector, using waste heat and introducing taxes on fossil fuels set more incentives in favor of $\mathrm{DH}[32,33]$

- country-specific fiscal schemes, legal regulations as well as spatially coordinated energy planning strategies are shaping the penetration of this technology [29]

Regarding the broad spectrum of possible applications as well as restrictions of $\mathrm{DH}$, there is the need to a) guide energy transition activities within the heating sector towards low carbon, b) promote the expansion of renewable energy and c) support planning authorities on the development of suitable heat supply systems. In order to be able to offer this kind of support and to foster the long-term economic and environmental feasibility of DHS in terms of affordable, acceptable and accessible energy, we identified four thematic areas playing a decisive role (displayed in Table 1): integrated spatial and energy planning (ISEP), costs, resources as well as environment and climate.

By interlinking these four areas, DHS feasibility can be holistically assessed by keeping urban structure, technological and economic options as well as environmental and climate protection in mind. Furthermore, social aspects are indirectly taken into account through this multi-layered consideration, since those energy systems and technologies might be supported and accepted by the public, which guarantee secure, resilient, clean and affordable energy while ensuring at least welfare neutrality [34]. Consequently, economic and environmental feasibility are not only fundamental to technological penetration but also determine social acceptance, e.g. through monetary benefits, novel employment opportunities, reduced pollution, and balanced ecosystems resulting from safe, reliable and decarbonized energy technologies [35].

Therefore, the following research question arises: How is it possible to take the issues ISEP, costs, resources as well as environment and climate into account and thus support future decision-making processes for DHS?

\section{Methods \\ Cross-disciplinary decisions in integrated spatial and energy planning}

In order to answer the research question on how to take the four levels ISEP, costs, resources as well as

Table 1 Four relevant areas for strategically support decisions on $\mathrm{DH}$ (own table)

Integrated spatial and energy planning (ISEP): Challenges always have a spatial relation, as do their solutions. Energy-related issues such as the efficient extraction, conversion, distribution, storage and use of energy as well as the choice of available technology need to be spatially coordinated. Here, the research field of "integrated spatial and energy planning" (ISEP) comes into action, dealing with the spatial dimension of energy supply and demand $[39,40]$. The consideration of energy related aspects in the course of spatial planning can significantly influence the energy supply, distribution and consumption as well as the associated greenhouse gas emissions through the strategic organization and control of functions and uses in space.

Resources: In line with the "Roadmap to a Resource Efficient Europe", EU Member States are called to remove barriers to resource efficiency. The roadmap claims to complement existing energy efficiency strategies for buildings with resource efficiency strategies that focus on a wider range of environmental impacts throughout the life cycle of buildings and infrastructure with sustainable use of materials and waste recycling [41]. In the light of heating systems, resources cover all materials that are bound by both the energy grids, the production sites as well as the buildings of the energy consumers. Here, type and age of the "building" under consideration influence the amount, composition and efficiency of the used materials. Consequently, the size of power plants, the length of needed pipelines and the need for rare, valuable or harmful materials play a central role.
Costs: Costs play a central role in the probability of technological conversion. In the end, potential heating systems will be attractive to both investors and customers if alternative options available for heating are associated with higher costs. This requires not only the consideration of the costs of heat generation, but also the construction of the network and the heat generation facilities. Focusing on the chosen technology, it depends on both technical and spatial conditions, whether a technology can be cost-efficiently installed at one specific place.

Those forms of energy carriers and technologies should be preferred which are regionally and/or locally available in order to reduce import costs and use potentials at hand, such as renewable energy, waste heat from sewage or industry and waste and sewage sludge incineration.

Environment and Climate: As briefly explained in the introduction, the energy system is a main driver of anthropogenic greenhouse gas emissions and thus the main cause of human-induced global warming $[23,42]$. Regarding direct and indirect effects through carbon-dioxideemissions, both the level of current energy consumption and, in particular, its composition plays a decisive role. The lower the energy consumption of our society, and the higher the share of renewable energy sources, the more emission-extensive and ecological compatible energy can be used.

On European Level, the most common form of heating is the use of gas in combination with a combustion boiler at home. This has to be critically scrutinized due to high emissions per kWh. Other forms like wood boiler, heat pumps or solar heating are based on renewable energy. DH represents a special from, since the needed heat load can be provided by a broad spectrum of local available energy carriers. These include waste and sewage sludge incineration, wood waste, straw as well as the utilization of waste heat by communities or industrial sites [43]. 
environment and climate into account, it is essential to evaluate which forms of valuation models are currently available for the analysis of DHS. Moreover, it needs to be clarified, whether the existing models consider and link the four areas of interest.

In recent years, numerous tools for planning practice have been developed to support the transformational processes within the energy system from a spatial planning perspective [36]. These planning tools serve the purpose of creating and homogenizing information rather than only collecting and preparing data. In the best case, tool application is able to trigger discussions, resulting in awareness-raising effects while supporting future planning decisions [37].

Resulting from various, disciplinary perspectives, planning tools show great differences in their thematic orientation, applicability, availability and manageability. Following characteristics of planning tools supporting transformational processes of the energy system had been identified over the last years (e.g. [38, 39]):

- Tools can help to evaluate the status quo, compare planning perspectives or use scenarios in order to cover a wide range of development perspectives.

- Tools can be based on qualitative arguments (checklists) and/or quantifiable facts (calculators). Depending on the type of decision, qualitative evaluations support a structured discussion, e.g. on how aspects should be implemented. In case of quantitative assessments, data can be calculated or estimated.

- Tools can be used in a variety of decision-making situations, both universally applicable or answering a very specific, narrowly defined issue. Additionally, different topics can be addressed: results may indicate direct spatial consequences, conflict potentials, $\mathrm{CO}_{2}$-emissions, ecological footprints or even economic aspects such as infrastructure cost or regional economic effects.

- Tools differ in terms of spatial perspective, as they can be implemented on regional, municipal, district, local, object or individual level. Due to the high level of complexity on the regional level, the number of available tools increases with smaller scales.

- Tools differ in their complexity and level of detail, ranging from rough estimations with few input parameters to complex models, based on a large number of detailed input, requiring precise knowledge of the particular situation.

- Tools generate a wide range of different results, such as new data sets or ratings. Some are capable of generating information about system interrelations from a factual and/or value point of view. Depending on the considered system relations and how aspects are integrated or omitted, different results are "produced". Therefore, both the chosen method as well as the form of input data lead to different results.

While there are great differences between tools, they all have one thing in common: the starting point and impetus for the development of a tool determines its later functionality and outcome. Due to the resulting conceptual, contextual and methodological differences, it is essential to understand what tools do (chosen methods) and why they do it (impetus and objectives of the developers) in order to apply them to concrete decision-making situation. The problem relies in the selection, interconnection and weighting of methods, input data and indicators, often only known to tool-developers and untouchable or invisible to users.

With regard to $\mathrm{DH}$, more and more planning tools had been developed within the last years [40-42]. In the sense of the above-mentioned characteristics, these tools often support detailed planning approaches such as the technical or the economic feasibility of DH (e.g. [43-46]). In some cases, spatial aspects are additionally implemented (e.g. [47-51]). However, there are no simple pre-evaluation methods available concerning whether a DHS is feasible on a selected location or not. Consequently, extensive data sets are essential in order to carry out evaluations using existing approaches. Furthermore, most of the planning tools focus on one of the subject areas identified in chapter "District heating", while missing out on interlinking them.

\section{The Eco.District.Heat-kit}

Given the lack of holistic planning models, the so called Eco.District.Heat-kit (EDHk) was developed on the example of the European member state Austria in the course of the $\mathrm{FFG}^{1}$-funded project "Eco.District.Heat" from 2016 until 2018. The EDHk represents a decision support model corresponding to the first stage of tool development, which discloses the impetus and objectives of its developers while staying adaptable to user- and regional-specific requirements.

More precisely, the EDHk assesses the possibilities and limits of DHS in urban areas considering both the four levels of interest as well as related attributes by focusing on basic input data available to users in an early planning stage. In order to make the relationships and mutual influences of these strongly divergent but cohesive levels and related attributes visible and verifiable, the EDHk combines two forms of valuation methods: "preference matrices" and "decision trees". Both methods are well established within environmental planning, such as landscape ecology, strategic management, environmental impact assessments (EIA) and strategic environmental 
assessments (SEA) to assess the potentials and limits of our environment [52, 53]. By applying and integrating these two methods, it becomes possible to incorporate both qualitative and quantitative aspects of DHS, while assessing and comparing the four relevant levels ISEP, costs, resources, and environment and climate.

\section{Preference matrices}

When using preference matrices, individual attributes are aggregated into abstract, overall features. This approach of merging individual characteristics into a final result is based on IF-THEN relations, regarding a chosen pair of attributes: "IF attribute 1 has the value A AND attribute 2 has the value B THEN both values can be aggregated to a total value of $\mathrm{A}$ ". Depending on the weighting of both attributes, the overall result can be shifted [54].

Therefore, preference matrices represent a method of prioritization, based on the pairwise aggregation, linking the factual and the value level while stimulating content-related discussions. In this context, the factual level describes measurable facts with regard to a specific topic and can be determined by valuation models. Consequently, the factual level corresponds to an approximation of reality. The value level denotes attitudes and opinions towards a certain issue $[55,56]$. By selecting relevant features, calibrating them and negotiating the weighting within the matrices, both facts and values can be considered within preference matrices.

Figure 6 illustrates the aggregation mode of a fictitious preference matrix. Two attributes (1 and 2$)$ are blended together by using four attribute classes (A to D). The number of classes can be even or odd and freely selected. The boundaries between the feature classes are also variable, but should be based either on already established limits or expert opinions. In any case, the class limits have to be disclosed in order to allow a transparent and comprehensive evaluation and to make facts and values behind the matrix visible.

The center of the matrix filled with valuations from $\mathrm{A}$ to $\mathrm{D}$ reflects the values of the linked attributes and results from the weighted intersection of rows (attribute 2) and columns (attribute 1). In the illustrated case, attribute 1 has a stronger influence on the rating than attribute 2 . In particular, the two attribute classes "1.1" and "1.2" of attribute 1 dominate those of the second attribute. The prioritization changes from attribute "1.3" onward. The chosen example shows, that positive ratings (here "A" and "B") dominate rating classes from C to D.

\section{Decision trees}

With the help of preference matrices, it is possible to merge two attributes, taking weighting and attribute classes into account. However, when aiming to describe and evaluate an entire system such as a DHS from a comprehensive point of view, it becomes necessary to link more than two attributes. Decision trees make it possible to rank and link different kinds of attributes or even preference matrices $[57,58]$. Herein, the ranking within the "tree" determines the value of the attribute or the preference matrix. Components, standing at the beginning of the evaluation chain are superimposed by successive components and therefore, will be dominated by their evaluation results. Figure 7 represents a decision tree, connecting multiple preference matrices:

\section{Attribute 1}

attribute class $1.1 \ldots$ value $A$ attribute class $1.2 \ldots$ value $B$ attribute class $1.3 \ldots$ value $C$ attribute class $1.4 \ldots$ value $D$

\section{Attribute 2}

attribute class $2.1 \ldots$ value $A$ attribute class $2.2 \ldots$ value $B$ attribute class 2.3...value $\mathrm{C}$ attribute class $2.4 \ldots$ value D

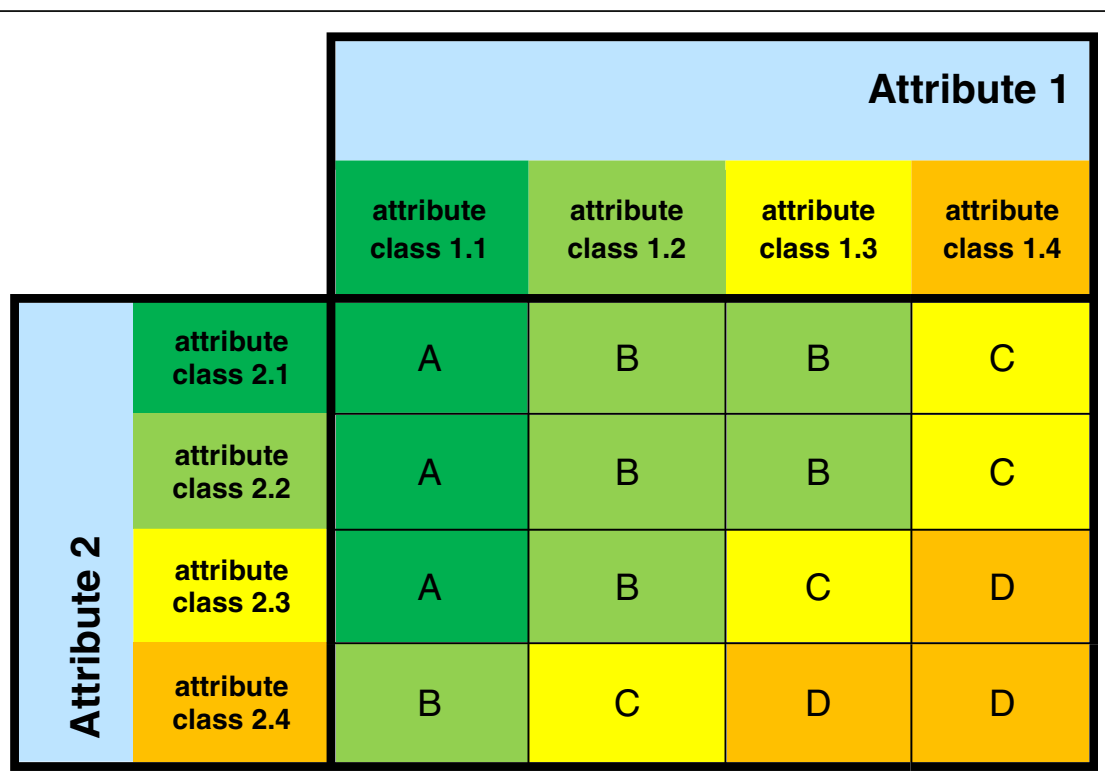

Fig. 6 Preference matrix with two attributes and four classes (own illustration) 


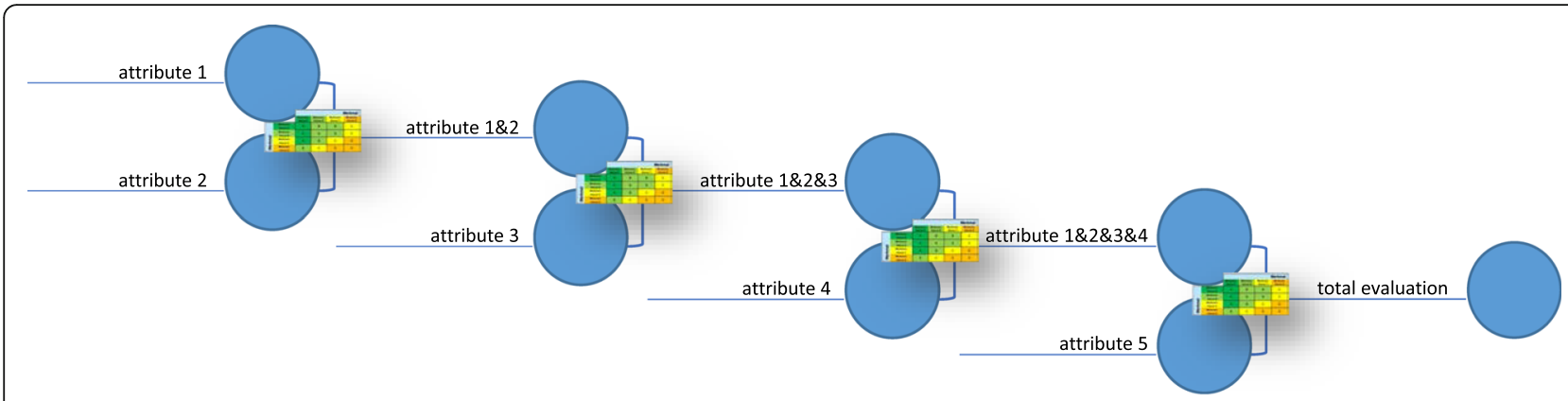

Fig. 7 Decision tree with five attributes and the intermediate preference matrices (own illustration)

Accordingly, the following procedure is to be followed when combining preference matrices and decision trees:

1. Collecting the attributes: All attributes important to the evaluation of a chosen topic need to be collected (e.g. literature review or review of existing models)

2. Determining the attribute classes: In order to make the pre-selected attributes assessable, attribute classes need to be defined

3. Ranking the attributes: With regard to the evaluation, the most important attributes have to be inserted at the end of the rating chain, while less important attributed should be started with. This ranking can be determined by using a decision tree

4. Linking pairs of attributes: Using preference matrices, the collected and ranked attributes should be aggregated into abstract, overall features.

\section{Implementation of the methods}

In the beginning of the research process, an interdisciplinary research team searched for district heating-related parameters in the context of Austria. The research group consisted of experts from the fields of spatial planning, integrated spatial and energy planning, energy economics, building and materials science. Based on a comprehensive literature review and expert knowledge, the research team identified 31 interdisciplinary parameters concerning DH. By using a modified version of the system analysis after Vester [59-61], the pairwise influence of these 31 parameters on each other was tested in order to evaluate the ability of parameters to influence (system drivers) or being influenced (control variables). The following eight parameters turned out to particularly influence DHS and therefore, are of special interest for the development of the EDHk: 1) type of the buildings to be supplied by DH, 2) mix of functions, 3) thermal insulation potential, 4) density of workplaces, 5) potential of compacting and extension, 6) building density, 7) population density and 8 ) used heat sources. The selection and evaluation process as well as the detailed definition of the eight influencing parameters and characteristics of the remaining parameters are documented in (Zach F, Erker S, Stoeglehner G: Factors influencing the environmental and economic feasibility of district heating systems - a perspective from integrated spatial and energy planning, unpublished).

Following the 31 parameters while especially focusing on the eight influencing ones, attributes were identified to form the centerpiece of the EDHk. In contrast to parameters, attributes correspond to measurable quantities. Therefore, attributes can either be congruent with the parameters itself or serve to describe them. Starting with a literature review, attribute classes were determined while necessary input data and calculation steps were defined.

Hereinafter, the attributes were ranked using decision trees and preference matrices. Together with national experts from energy and urban planning practice, the identified attributes, the attribute classes, the input data, the calculation steps as well as the rules of aggregation within the individual matrices had been discussed, reflected and eventually adapted. In particular, attention was paid to the integration of scientific knowledge and practical knowledge.

Finally, the applicability of the model as well as the reliability of its results were tested, based on eight heterogeneous case study areas in Austria (see [62]). Additional insights and findings had been incorporated into the model and completed the development of the EDHk in June 2018.

In accordance with this approach, 42 attributes and 35 matrices had been developed and integrated into the EDHk (see Additional files 1, 2 and 3). Additionally, a list of required input data and possible calculation approaches to determine the attribute classes can be found in the appendix. By following the methodological insights of the EDHk in this chapter and using the Additional files 1, 2 and 3, the interdisciplinary decision support model for grid-bound heat supply systems in urban areas can be applied. 


\section{Results}

The EDHk represents an interdisciplinary decision support model to evaluate the long-term suitability of DHS in urban areas. Therefore, the result section is dedicated to the description of this novel approach. First, relevant framework conditions for the EDHk are determined. Second, the selected attributes, required data inputs and the rules of aggregation are elucidated. By applying the EDHk, the sections ISEP, costs, resources as well as environment and climate gradually come together to form a holistic picture of the DHS under evaluation. Potentials and restrictions of DHN on a selected site become visible. Finally, the implementation of an overall rating is discussed in the third section.

\section{Framework conditions}

In order to ensure a high level of applicability, essential framework conditions need to be clarified before the actual evaluation starts. Otherwise, decision models can quickly lead to ambiguity and frustration among its users. Accordingly, we dedicate this section to the following two points: preparatory data collection and rules for delimitating and subdividing the project area.

Before applying the EDHk, relevant input data has to be collected. Knowledge concerning the urban district as well as the existing and/or planned heating supply system is decisive for the successful and optimal use of the EDHk. Central inputs are listed in the Additional file 2. The more data about the planning project and the planning area is available, the more conclusions can be drawn from the results with regard to subsequent effects as well as implementation and improvement potentials. In any case, users benefit from local knowledge in order to estimate eventually unavailable data. As the EDHk was developed on the example of Austria, input data and calculation steps are state-specific. However, we focused on the integration of widespread data (e.g. by EuroStat) in order to transfer the EDHk to further spatial contexts.

Subsequently, a detailed delimitation of the project area has to be followed. This includes all areas that are directly affected by the planned $\mathrm{DH}$ project, such as existing residential, service and industrial buildings as well as future settlement development projects. Excluded are those areas without any relevance to the planning project until 2050. After delimiting the project area, it has to be subdivided into a maximum of five homogeneous subareas in order to ensure manageability of the results. This subdivision has to be based on urban planning principles: At the beginning, a distinction should be made between building land and grassland. Small-scale green areas are to be assigned to the corresponding construction areas. Thereinafter, the building land can be differentiated with regard to its current (colored buildings) or planned (black and white buildings) predominant use, while the following categories can be considered: "housing", "services", and "production". The final differentiation is based on the most dominant building type, corresponding to the usable floor space per area. Here, a distinction can be made between "single-family houses", "terraced houses", "multi-story buildings", and "industrial and commercial buildings". The following figure shows a possible subdivision into multiple subareas (see Fig. 8).

After a) the necessary gathering of data and information on the DH project and the planning area and b) the delimitation and subdivision of the project area into a maximum of five subareas, case study settlements can be evaluated by the EDHk.

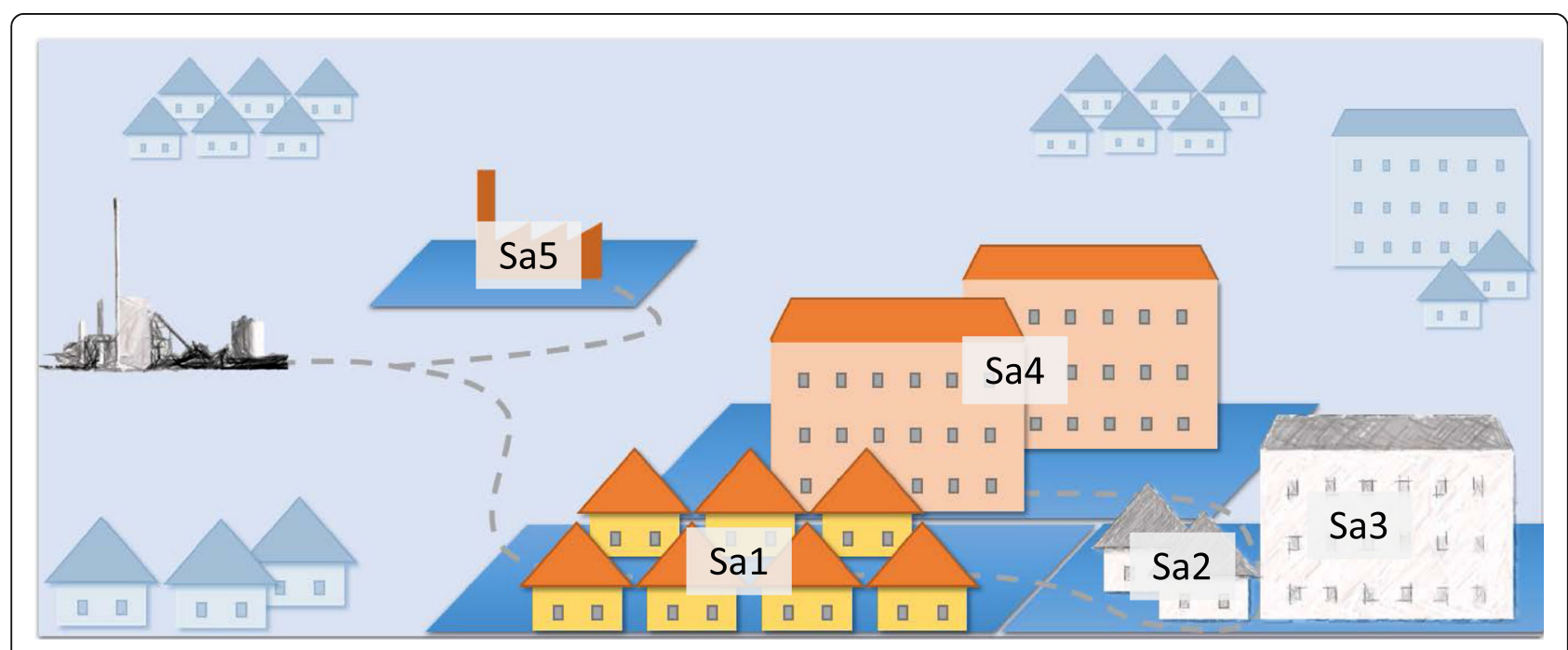

Fig. 8 Possible steps to delineate up to five assessable subareas (Sa1 to 5) by dominant type of use and building. Areas in dark blue (own illustration) 


\section{Assessment of district heating relevant attributes}

In order to give insights on both the impetus and objectives as well as the methodology and functionality of the EDHk (see Cross-disciplinary decisions in integrated spatial and energy planning), the following subchapters will illustrate why certain attributes were chosen. Furthermore, questions about i) how the chosen attributes can be estimated by selected input data and calculation steps and ii) how estimated attributes might be aggregated by using preference matrices will be answered in the Additional files 2 and 3.

\section{Embedding the project in a planning period}

In order to start the evaluation, general information about the project unfolding validity across all four levels is needed. This includes information on possible development scenarios such as trends of building refurbishment, population growth as well as possible effects of climate change up to 2050. All of these scenarios can significantly influence the future possibilities of $\mathrm{DH}$ within the urban district under investigation and should be roughly estimated.

\section{Integrated spatial and energy planning}

In order to evaluate the spatial feasibility of DHS, both relevant and easily assessable attributes in the Austrian context were selected. After several iterative coordination processes within the research project, 17 attributes for ISEP had been defined, based on 41 entries (input data) and the methods described in chapter "Preference Matrices". The exact linkages of attributes, input data and calculation steps can be taken from the Additional files 2 and 3.

Concerning the topic ISEP, the research team focused on information about 1) heat consumers and heating demand (location analysis), 2) the distribution of energy (grid analysis) as well as 3) the potential heat sources (heat source analysis). These three areas determine, whether the selected settlement is suitable for a DHS or not from a spatial and technical perspective.

At first, knowledge concerning the attributes "heat demand", "heat demand density", "mix of functions" and "mixed system use" is necessary to estimate whether the existing heat requirements justify the long-term implementation of a grid-bound heat supply system [63]. Taking into account qualitative and quantitative input data concerning "building typology", "the share and type of predominant utilization" and the "construction period" of buildings, important estimations concerning the heat demand can be carried out. In combination with the "size of each subarea" and information concerning the "development scenarios" up to 2050, the results of the consumer related analysis can be refined. By reporting potential "high temperature process heat demand", "space heat demand" and "hot water demand" of the industry and service sector, the EDHk is able to evaluate the attributes "heat demand per year" with regard to high temperature heat, space heat and hot water, the "heat demand density" as well as the "mix of functions". Finally, it must be clarified whether there should be a mixed system use e.g. by additionally implementing district-cooling.

Secondly, inputs concerning existing and planned network infrastructure are required to estimate whether the network lengths and the degree of utilization justify the use of a DHS due to associated heat losses and an efficient use of space $[27,64]$. In that sense, the "type of network", its "lengths" and the "planned degree of connection" play an important role when it comes to later suitability of DHS. By incorporating previous inputs, the EDHk can determine the occupancy density in GWh per kilometer and year, which is crucial for the efficient operation of a grid-bound heating network. In addition, the network specifications will be used to determine whether there is a parallel operation of a gas and a DHS. Considering fundamental parts of a resilient energy system, such as redundancy and diversity, a parallel network structure will be positively assessed from an energy security point of view, while occupancy rates might suffer from duplicate structures. Subsequently, information on the "possible cascading use" of heat is required. The cascading use of heat not only ensures efficient energy use, but also avoids the installation of non-essential energy generation and distribution systems, whereby land consumption can be minimized.

The last part of the ISEP evaluation focuses on the analysis of the potential heat sources for DHS. It is necessary to estimate the heat potential across all subareas and set them in relation to the heat requirements and the potential distribution network. Thus, the potential of locally available heat supply in GWh/a needs to be assessed, distinguishing between decentralized and centralized technologies as well as fossil and renewable energy sources. Depending on the availability of the chosen heat sources, the level of heat to cover process heat, space and / or hot water demands can be assessed. Finally, the availability of "energy storage devices" needs to be assessed in order to evaluate the potential of compensating possible fluctuations in production or consumption.

If either (a) the total heat demand is deficient (location analysis), (b) the heat demand density is too low (site analysis), (c) the network structure is inefficient (grid analysis) or (d) not enough heat sources are available (heat source analysis) the overall rating of this section will be negative. If the mentioned requirements are (sufficiently) fulfilled, the further evaluations concerning the subsequent levels costs, resources, and environment and climate can be carried out. 


\section{Costs}

The goal of the costs section is to evaluate the most cost-effective DHS. For this purpose, both already specified attributes and new user-inputs are taken into account. The cost evaluation is based on five additional entries and eleven attributes that are blended to form an overall result.

Already specified scenarios with regard to "settlement developments" and "building refurbishments" are incorporated in the cost evaluation. Both scenarios pose an indirect influence on the suitability and the costs of grid-bound heat supply systems. In addition to the scenarios, the attributes "mix of functions", "implementation of district cooling systems", "redundant network operations (resilience)" and the calculated "occupancy density" from the previous spreadsheet are included in the cost evaluation. While "the mix of functions" has a positive effect on the temporal distribution of heat demand and thus the efficient supply of areas, the "use of district cooling systems" and "redundant grid operations" have negative impacts on the costs. Less clear conclusions can be drawn from the "occupancy rate" which can have both positive or negative effects on costs depending on its amount. The limit value for (cost) efficient operation requires more than $2 \mathrm{GWh}$ per kilometer and year.

Besides these already evaluated attributes, additional inputs are essential for the economic evaluation. The "construction period of the DHN" is used to estimate the "pipe costs". Recently built networks with better insulation comprise higher costs per kilometer pipe length. Likewise, the "sealing of the pipeline corridor" has an effect on the costs. Unsealed surfaces are associated with lower costs than sealed surfaces. Likewise, "height level differences" have an impact on the costs of network construction. If there are height differences of $40 \mathrm{~m}$ and more, both the network construction and the operation (due to increased pressure) are uneconomical [64]. In addition, the "intended supply temperature level" and the "costs for the primary energy source" have an influence on the operating costs. The higher the temperature level or the costs for primary energy sources, the more expensive the operation of the system becomes.

Finally, the factor "occupancy density" influences cost-effectiveness of the potential DHS. If the density of a subarea is below 0.5 , both the supply of new buildings and non-refurbished old buildings is presumably uneconomical. The exact calculation steps to evaluate attributes by input data as well as the rules for aggregation can be found in the Additional files 2 and 3.

\section{Resources}

Similar to the evaluation of the costs, the resource assessment is based on previously established values and novel input data. Since most of the information needed for the evaluation of the resource-efficiency within DHS is covered by the former sections, only three further inputs are additionally required. Overall, the resource assessment is based on the intersection of seven attributes.

On the basis of the pre-defined values the EDHk evaluates, whether the information on the scenarios up to 2050 has led to a "change in the building stock" or to "building refurbishment". Both the creation of new buildings (residential, industrial or service) and the thermal insulation of the building substance pose negative effects, due to the additional use of materials. Similar rules apply to the evaluation of the "use of district cooling systems" and the "creation of redundant network infrastructures". Both entail an additional expenditure of resources and thus mean a worsening of the present result.

The resource assessment is completed by including effects of the planed network structure and its design. Here, "the nominal pipe diameter" concerning both the existing and the planed DHN as well as the planed gas network comes into focus. Additionally, the "length of the planed network" and "the construction period of the DHN" are evaluated. The larger the diameter and the more recent the network was installed the more material is required.

Besides the intersection of seven basic characteristics, the resource section additionally may offer quantitative output on the matter of resources used for the building stock and the DHN in tons. However, it wasn't possible to transform these values into the established quantitative rating model. Therefore, the values on tons material used per building stock and DHS can be calculated for informational propose.

\section{Environment and climate}

Finally, the assessment of environmental and climate-related aspects is based on existing data inputs and intersects seven previously evaluated attributes.

At the beginning, the kit examines whether the general information indicates a "modified building stock" or a "building refurbishment". Both the construction of residential, industrial or service buildings and the thermal renovation result in an increase of resource consumption, which translates into an increased ecological footprint and therefore, negative effects on the environment.

Finally, the "use of district cooling systems", the "nominal pipe diameter", "the construction period of the DHN" and "creation of a redundant network structure" are evaluated. All four features entail additional resources, consequently worsening the final rating results.

The evaluation concludes with an estimation of the use of renewable energy sources (RES) related to total heating supply. According to the information given in the ISEP section, the EDHk evaluates the contribution of 
regenerative energy sources. The higher the share of renewables, the better the final rating.

Noteworthy, a detailed evaluation of the greenhouse gas emissions concerning different energy sources and buildings was not feasible, due to the ranking of emissions: It was not clear where to draw the limits for high or acceptable emissions. Every additional ton of $\mathrm{CO}_{2}$-equivalent is harmful from a climate and environmental perspective. Therefore, emissions resulting from a planned DHS can be calculated for informational purpose but are not included in the ranking itself.

\section{Overall rating}

In the end, the partial results per subarea need to be merged. This corresponds to a weighted aggregation, which is based on the size of the respective subarea. Here, large partial areas have a higher impact on the final result than comparatively smaller structures. Therefore, a large, positively valued subarea can compensate a small area and can help the overall project in achieving a "positive" rating.

If the overall rating does not achieve the desired result, users may overthink their inputs within the subareas in the individual result categories ISEP, costs, resources and environment and climate. In order to improve a non-optimal result (and thus the overall result), the following actions should be considered: On the one hand, siting influences all the results affected by location-related characteristics, such as building density, the existing building substance or the prevailing degree of sealed pipeline corridors. On the other hand, planning related measures can improve the result. This includes project-specific changes such as type of planned network, lengths of pipelines or forms of heat sources. It should be noted that the adaptation of single inputs might improve individual aspects, but do not necessarily lead to an optimization of the overall result. For example, the creation of new buildings can guarantee the necessary heat demand to operate a network, whereas the new construction has a negative impact on the costs. In addition to the modification of individual values, negative rated subareas can be excluded from the overall rating in order to achieve a better overall result. However, this is only recommended if e.g. the exclusion of one subarea does not lead to an interruption of the network. Subsequently, the kit enables "experimenting" with individual values and visualizes connections and interlinkages of relevant system attributes.

\section{Discussion}

The anthropogenic climate change increases the need for a transformation of the urban heat supply system. Especially with regard to future urban developments, such as the conversion and densification of existing urban structures as well as the extension in fringe areas, DHSs are seen as an opportunity to redesign our heat supply system. In order to support DH-related development processes, a variety of possible methodological approaches and planning tools can be found. However, these tools often focus on purely technical or economic aspects of the planned network structures, while disregarding a holistic assessment of the system. Consequently, approaches allowing a first evaluation concerning the suitability for DHS are widely missing. Likewise, cross-thematic approaches are barely available, interconnecting e.g. spatial, technical, economic and ecological aspects.

Due to these research gaps, the EDHk was developed, representing an interdisciplinary, strategic decision-support model, capable of assessing urban areas with regard to their long-term suitability for DHS. By offering a transparent evaluation model, the EDHk might serve as a basis for discussion for all planning participants. Since decisions regarding technical infrastructure could have far-reaching and long-term effects on surrounding areas, preliminary assessments are essential for strategic planning decisions. To achieve the utmost benefits of the EDHk and to profit from the early recognition of potential problems, it has to be applied early in the planning process. In addition to the potentials of preliminary assessments, the kit offers an intertwined consideration of relevant aspects that are usually analyzed separately. In particular, the interdisciplinary cooperation of research institutions with thematic expertise in the fields of energy planning, spatial planning, economics, resources and ecology supported the successful development of a versatile planning kit. Due to the consideration of multifaceted disciplines, the EDHk unfolds benefits for different target groups, including energy supply companies, planners, decision-makers, but also private individuals affected by any planned DHN. By creating a common basis for decision-making and for these different target groups, the EDHk enables its potential users to identify planning hotspots and to act proactively. Concluding, the following advantages of the EDHk approach can be highlighted:

- identifying basic DH relevant variables and interlinking them

- disclosing both the basic variables and the evaluation methods behind EDHk

- considering both qualitative and quantitative data

- creating awareness for the relations between different aspect

- comprehensively evaluating DH planning projects

- comparing different planning locations for DH

- adjusting different system variants in the course of the assessment to gradually improve the rating 
- offering a time-efficient assessment due to its preliminary character

- altering the methodological approach due to its high level of flexibility

- triggering discussions due to its strategical character

- supporting a wide range of potential target groups

- homogenizing the basic knowledge on DHS

As part of the modeling, it has to be noted that ISEP was of particular importance. Since the energy transition can be understood as geographically-constituted process [65], ISEP served as the foundation of modeling. Due to its cross-sectional orientation, the geographical components regarding energy demand, supply and network structure build the basis for the later evaluation of technical, economic, resource-specific and environmental aspects. Only by assessing local predispositions at first, the former aspects can be evaluated. In course of the further kit design, we came across a logical hierarchy of aspects since most of them are more or less interdependent. Therefore, the development of the Additional files 1, 2 and 3 significantly helped to create a coherent evaluation model. Furthermore, the documentation of the decision steps supported the discussion process within the research group as well as with external partners. New considerations could quickly be visualized and eventually be adapted.

Besides its benefits it is essential to mention limitations of the EDHk. As illustrated above, the EDHk has the purpose of pre-evaluating DHSs. Therefore, it is essential to understand that the kit is not capable of replacing detailed planning. This would require a different set of methods to process more detailed input data. The EDHk has to be understood as the first part of a long evaluation process. Following this, one particular pitfall has to be considered: the proposed classification using four rating classes from "A" to "D" might blur the final result. For instance, "A" rated subareas might be close to a " $\mathrm{B}$ " rating, whereas " $\mathrm{B}$ " ratings could be close to an " $\mathrm{A}$ " or " $\mathrm{C}$ " rating and so on. When linking the ratings, this appears to be a methodological deficit. It must be noted that particularly close results can lead to misleading conclusions. Therefore, a subsequent detailed planning becomes inevitable.

Furthermore, the methodical shortcomings of the resource and the environment and climate section must me mentioned. Here, quantitative information could be provided concerning the use of resources as well as the associated $\mathrm{CO}_{2}$-emissions and the ecological footprint. However, a qualitative rating of these values was not feasible. This results from the fact that any additional resource consumption and the associated impacts on environment and climate had to be rated "negative", while no grading of the rating was possible at the time: How much resource consumption is acceptable and when is it too much from a material and environmental point of view? By finding a suitable indicator for the efficient use of resources and the associated impacts on environment and climate, the rating of all four areas could be homogenized.

Besides the development of an interdisciplinary method, a prototype for internal use was created in Excel in the course of the research project. Here, project- and site-specific data can be entered, whereas the basic information required for the evaluation of selected attributes is separated and can be shown when required. Based on the approach of [62], case study areas of already existing and planned DHNs were used to analyze whether the model is fully functional and leads to realistic results. Resulting from this, the model was continuously improved. This prototype is not yet open access, since it was only applied under the supervision of developers, while overlooking e.g. later user-friendliness, accessibility, design or IT basics. However, to increase the usability of the chosen methods, a prototype for external use should be developed. As part of further research, it should be considered to develop the prototype e.g. by creating a Web or a GIS application, while keeping applicability, availability and manageability in mind.

\section{Conclusions}

The aim of the research project "Eco.District.Heat" was to develop an interdisciplinary, strategic decision support to assess district heating supply systems on urban level. For this purpose, energetic, spatial, environmental, material and ecological aspects as well as qualitative and quantitative criteria were integrated in order to create a holistic model.

Using the EDHk, existing or planned urban areas can be modeled and analyzed on the basis of selected criteria with regard to their long-term suitability for DHSs. In line with this, scenarios are integrated into the evaluation model in order to be able to consider possible development paths until 2050 and thus evaluating the long-term suitability of DHSs. With the kit, users are capable of optimizing long-term $\mathrm{DH}$ projects early before decisive framework conditions have been determined, preliminary decisions made and detailed planning had begun. Subsequently, the EDHk emphasizes those aspects, which require special attention in the further planning process.

Based on the analysis of the EDHk, the users receive a benchmarked result, ranging from A (very good) to D (needs improvement) as well as additional quantitative information. According to the final rating, the users of the kit can reflect on planning steps and coordinate their further course of action. Accordingly, a negative overall result or partial result by the EDHk does not mean that a planning option or a location has to be excluded from 
further evaluations. Rather such a result indicates the need for improvement of the project and points to the necessary adaptation measures at the planning location. Early in the planning process and thus, before a formal planning procedure has been started, the EDHk illustrates where urban areas might be suitable for $\mathrm{DH}$ from a technical point of view or should be kept free from project development due to disproportionately negative effects on costs, the environment or resources. In many cases, non-optimal planning outcomes can be avoided before long-lasting decisions have been made. Finally, informal planning considerations can be transferred to the formal planning processes through the use of the EDHk.

\section{Endnotes}

${ }^{1}$ The Austrian Research Promotion Agency (FFG) represents the national funding agency for industrial research and development in Austria [74].

\section{Additional files}

Additional file 1: The four Decision Trees of the EDHk. (PDF $82 \mathrm{~kb}$ )

Additional file 2: Needed data input, units and descriptions for subsequent evaluation of the attributes within the EDHk. (PDF $114 \mathrm{~kb}$ )

Additional file 3: Matrices and Classifications of the EDHK. (PDF $151 \mathrm{~kb}$ )

\section{Abbreviations}

DH: District Heating; DHN: District Heating Network; DHNs: District Heating Networks; DHS: District Heating System; DHSs: District Heating Systems; EDHk: Eco.District.Heat-kit; ISEP: Integrated Spatial and Energy Planning

\section{Acknowledgements}

The authors would like to thank the entire project team of "Eco.District.Heat" as well as the Advisory Board Members for the accompaniment of the research processes. Findings, conclusions and recommendations within this paper reflect results of the original study, and represent a content-related development and post-processing of research results.

\section{Funding}

This paper is based on findings from the project "Eco.District.Heat Potenziale und Restriktionen leitungsgebundener Wärmeversorgung in Stadtquartieren" (Project No 854673). The project is funded by the Austrian Ministry of Transport, Innovation and Technology (BMVIT) within the program "Stadt der Zukunft" of the Austrian Research Promotion Agency (FFG). The funding body had no role in data collection, analysis, and interpretation of data as well as in writing the manuscript.

Due to funding regulations, we are instructed to include the following paragraph: "Stadt der Zukunft ist ein Forschungs- und Technologieprogramm des Bundesministeriums für Verkehr, Innovation und Technologie. Es wird im Auftrag des BMVIT von der Österreichischen Forschungsförderungsgesellschaft gemeinsam mit der Austria Wirtschaftsservice Gesellschaft $\mathrm{mbH}$ und der Österreichischen Gesellschaft für Umwelt und Technik ÖGUT abgewickelt".

\section{Availability of data and materials}

All sources of data and materials analyzed in the course of this paper are listed in the reference section. Newly generated data and materials such as indicators and rules of classification for the EDHK can be found either in the article itself or in the supplementary materials (Additional files 1, 2 and 3). Additional information on the selection process of the indicators are documented in (Zach F, Erker S, Stoeglehner G: Factors influencing the environmental and economic feasibility of district heating systems - a perspective from integrated spatial and energy planning, unpublished). Further information on the applicability of the EDHk can be found in
Lichtenwoehrer et al. (2019): Future compatibility of district heating in urban areas - a case study analysis in the context of integrated spatial and energy planning.

\section{Authors' contributions}

SE took a lead in the write-up of the article, performed a literature analysis and interpreted data and materials relevant to this research. She led the development of the EDHk and designed a Beta Version for internal use. PL contributed case study experiences to the tool development, lectured the article and supported the preparation of the supplementary materials. Furthermore, PL tested the EDHK to ensure its functionality. FZ had a central part within the research project Eco.District.Heat and gave input to technical and economic aspects concerning district heating systems. GS coordinated the research project Eco.District.Heat, contributed knowledge to integrated spatial and energy planning as well as the development of planning and assessment methods. He contributed to conceptualizing and revising the paper. All authors read and approved the final manuscript.

Ethics approval and consent to participate

Not applicable.

\section{Consent for publication}

Not applicable.

\section{Competing interests}

The authors declare that they have no competing interests.

\section{Publisher's Note}

Springer Nature remains neutral with regard to jurisdictional claims in published maps and institutional affiliations.

\section{Author details}

${ }^{1}$ Institute of Spatial Planning, Environmental Planning and Land Rearrangement, University of Natural Resources and Life Sciences, Vienna, Peter-Jordan-Strasse 82, 1190 Vienna, Austria. ${ }^{2}$ Austrian Energy Agency, Mariahilfer Strasse 136, 1150 Vienna, Austria.

Received: 10 October 2018 Accepted: 20 February 2019

Published online: 29 March 2019

\section{References}

1. Mattick CS, Williams E, Allenby BR (2010) Historical trends in global energy consumption. IEEE Technol Soc Mag 29:22-30. https://doi.org/10.1109/MTS. 2010.938106

2. Varfolomeyev SD, Gurevich KG (2001) The Hyperexponential growth of the human population on a macrohistorical scale. J Theor Biol 212:367-372. https://doi.org/10.1006/jtbi.2001.2384

3. Häußermann H, Siebel W (2004) Stadtsoziologie: Eine Einführung. Campus Verlag, Frankfurt/Main

4. Schäfers B (2010) Stadtsoziologie: Stadtentwicklung und Theorien Grundlagen und Praxisfelder. Springer-Verlag, Wiesbaden

5. UNFPA, DSW (2011) Weltbevölkerungsbericht 2011. Bevölkerungsfonds der Vereinten Nationen. Deutsche Stiftung Weltbevölkerung, Hannover

6. Grübler A (2004) Transitions in energy use. In: Encycl Energy, Laxenburg

7. Medlock KB, Soligo R (2001) Economic development and end-use energy demand. Energy J 22:77-105

8. Michaelides E (2012) Alternative energy sources. Springer Science \& Business Media, Fort Worth

9. BP (2018) BP statistical review of world energy 2018,67 th edn. BP p.L.C, London

10. IEA (2017) Key world energy statistics 2017. International Energy Agency and Organisation for Economic Co-operation and Development, Paris Cedex

11. EIA (2017) International energy outlook 2017. U.S. Energy Information Administration, Washington DC

12. IPCC (2015) Climate change 2013. The physical science basis. Technical summary. IPCC, Geneva

13. European Commission (2015) Communication from the commission to the European Parliament and the council. The Paris protocol - a blueprint for tackling global climate change beyond 2020. COM (2015) 81 final/2 
14. UNFCCC (2008) Kyoto protocol. Reference manual on accounting of emissions and assigned amount. United Nations Framework Convention on Climate Change, Bonn

15. United Nations (2015) Paris agreement, Paris

16. United Nations (1998) Kyoto Protocol to the United Nations Framework Convention on Climate Change

17. IEA (2016) Energy Technology Perspectives 2016, Paris Cedex

18. Stoeglehner G, Neugebauer G, Erker S, Narodoslawsky M (2016) Integrated spatial and energy planning: supporting climate protection and the energy turn with means of spatial planning. Springer, Vienna

19. Eisentraut A, Brown A (2014) Heating and cooling without warming. Market Developments and Policy Considerations for Renewable Heat. Featured Insight. International Energy Agency, Paris Cedex

20. Isaac M, van Vuuren DP (2009) Modeling global residential sector energy demand for heating and air conditioning in the context of climate change. Energy Policy 37:507-521. https://doi.org/10.1016/j.enpol.2008.09.051

21. Werner S (2006) The new European Heating Index. Effects on DH from directives, laws and regulation. Chalmers University of Technology, Göteborg

22. Tsikaloudaki K, Laskos K, Bikas D (2011) On the establishment of climatic zones in Europe with regard to the energy performance of buildings. Energies 5:32-44. https://doi.org/10.3390/en5010032

23. European Commission (2012) An EU Strategy on Heating and Cooling

24. Werner S (2017) International review of district heating and cooling. Energy 137:617-631. https://doi.org/10.1016/j.energy.2017.04.045

25. Keirstead J, Shah N (2013) Urban energy systems: an integrated approach. Routledge, London

26. Lund H, Werner S, Wiltshire R, Svendsen S, Thorsen JE, Hvelplund F, Mathiesen BV (2014) 4th Generation District heating (4GDH): integrating smart thermal grids into future sustainable energy systems. Energy 68:1-11. https://doi.org/10.1016/j.energy.2014.02.089

27. Nussbaumer T, Thalmann S, Jenni A, Ködel J (2017) Planungshandbuch Fernwärme. Bundesamt für Energie BFE, Bern

28. Bruns E, Futterlieb M, Ohlhorst D, Wenzel B (2012) Erneuerbare Energien in Wärmenetzen - eine realistische Perspektive? Z Für Energiewirtschaft 36: 159-172. https://doi.org/10.1007/s12398-012-0087-z

29. European Commission (2016) Mapping and analyses of the current and future (2020 - 2030) heating/cooling fuel deployment (fossil/ renewables). In: Work package 1: Final energy consumption for the year 2012

30. Colmenar-Santos A, Rosales-Asensio E, Borge-Diez D, Blanes-Peiró J-J (2016) District heating and cogeneration in the EU-28: current situation, potential and proposed energy strategy for its generalisation. Renew Sust Energ Rev 62:621-639. https://doi.org/10.1016/j.rser.2016.05.004

31. Sayegh MA, Danielewicz J, Nannou T, Miniewicz M, Jadwiszczak P, Piekarska K, Jouhara H (2017) Trends of European research and development in district heating technologies. Renew Sust Energ Rev 68:1183-1192. https:// doi.org/10.1016/j.rser.2016.02.023

32. Magnusson D (2012) Swedish district heating - a system in stagnation: current and future trends in the district heating sector. Energy Policy 48 449-459. https://doi.org/10.1016/j.enpol.2012.05.047

33. Lake A, Rezaie B, Beyerlein S (2017) Review of district heating and cooling systems for a sustainable future. Renew Sust Energ Rev 67:417-425. https:// doi.org/10.1016/j.rser.2016.09.061

34. Cohen JJ, Reichl J, Schmidthaler M (2014) Re-focussing research efforts on the public acceptance of energy infrastructure: a critical review. Energy 76: 4-9. https://doi.org/10.1016/j.energy.2013.12.056

35. Stigka EK, Paravantis JA, Mihalakakou GK (2014) Social acceptance of renewable energy sources: a review of contingent valuation applications. Renew Sust Energ Rev 32:100-106. https://doi.org/10.1016/j.rser.2013.12.026

36. Stöglehner G, Erker S, Neugebauer G (2013) Tools für Energieraumplanung. Ein Handbuch für deren Auswahl und Anwendung im Planungsprozess. Bundesministerium für Land- und Forstwirtschaft, Umwelt und Wasserwirtschaft, Wien

37. Stöglehner G, Erker S, Neugebauer G (2013) Tools für Energieraumplanung UVP-Report, Wien

38. Abart-Heriszt L, Erker S (2018) Österreichweite Energieverbrauchs- und Treibhausgasemissionsdatenbank auf Gemeindeebene. Austria-wide Energy Consumption and Greenhouse Gas Emissions Database on Municipal Level. AGIT 4 2018:6, Vienna

39. Stoeglehner G, Neugebauer G, Erker S, Narodoslawsky M (2016) Processes and Tools for Integrated Spatial and Energy Planning. In: Integrated Spatial and Energy Planning: Supporting Climate Protection and the Energy Turn with Means of Spatial Planning. Springer, Wien

40. Allegrini J, Orehounig K, Mavromatidis G, Ruesch F, Dorer V, Evins R (2015) A review of modelling approaches and tools for the simulation of districtscale energy systems. Renew Sust Energ Rev 52:1391-1404. https://doi.org/ 10.1016/j.rser.2015.07.123

41. Castaldo VL, Pisello AL (2018) Uses of dynamic simulation to predict thermal-energy performance of buildings and districts: a review. Wiley Interdiscip Rev Energy Environ 7. https://doi.org/10.1002/wene.269

42. Dermentzis G, Schnieders J, Pfluger R, Pfeifer D, Feist W, Ochs F (2017) An overview of energy district tools in Europe and the importance of an equivalent heating reference temperature for district simulations. Bauphysik 39:316-329. https://doi.org/10.1002/bapi.201710036

43. Bachmaier A, Narmsara S, Eggers J-B, Herkel S (2016) Spatial distribution of thermal energy storage systems in urban areas connected to district heating for grid balancing - a techno-economical optimization based on a case study. J Energy Storage 8:349-357. https://doi.org/10.1016/j.est.2016.05.004

44. del Hoyo Al, Herrero López S, López Perez S, Rämä M, Klobut K, Febres JA (2018) Models for fast modelling of district heating and cooling networks. Renew Sust Energ Rev 82:1863-1873. https://doi.org/10.1016/j.rser.2017.06.109

45. Huang $H$, Ooka R, Kato S (2005) Urban thermal environment measurements and numerical simulation for an actual complex urban area covering a large district heating and cooling system in summer. Atmos Environ 39:6362-6375. https://doi.org/10.1016/j.atmosenv.2005.07.018

46. Lund H, Möller B, Mathiesen BV, Dyrelund A (2010) The role of district heating in future renewable energy systems. Energy 35:1381-1390. https:// doi.org/10.1016/j.energy.2009.11.023

47. De O, Schneider S, Quiquerez L, Lachal B, Hollmuller P (2017) Spatial and temporal characterization of energy demand and resources for an existing and dense urban district in Geneva, pp 259-264

48. Delmastro C, Martinsson F, Mutani G, Corgnati SP (2017) Modeling Building Energy Demand Profiles and District Heating Networks for Low Carbon Urban Areas, Procedia Engineering 198 (2017), pp 386-397

49. Girardin L, Marechal F, Dubuis M, Calame-Darbellay N, Favrat D (2010) EnerGis: a geographical information based system for the evaluation of integrated energy conversion systems in urban areas. Energy 35:830-840. https://doi.org/10.1016/j.energy.2009.08.018

50. Nageler $P$, Schweiger $G$, Schranzhofer $H$, Mach T, Heimrath $R$, Hochenauer $C$ (2018) Novel method to simulate large-scale thermal city models. Energy 157:633-646. https://doi.org/10.1016/j.energy.2018.05.190

51. Olsen PK, Lambertsen H, Hummelshøj R, Bøhm B, Christiansen CH, Svendsen S, Larsen CT, Worm J (2008) A new low-temperature district heating system for low-energy buildings, In Proceedings of the11th International Symposium on District Heating and Cooling, Reykjavik

52. Kamiske GF (2015) Handbuch QM-Methoden: Die richtige Methode auswählen und erfolgreich umsetzen. Carl Hanser Verlag GmbH Co KG, München

53. Quelle G (2012) Planen Führen Wachsen: Mit Methode zum Erfolg. BoD Books on Demand, Dortmund

54. Fürst D, Scholles F (2008) Handbuch Theorien und Methoden der Raumund Umweltplanung. Rohn

55. Erker S (2017) Spatial Resilience in the light of energy crises. A concept for integrated spatial and energy planning. Cumulative dissertation. University of Natural Resources and Life Sciences, Vienna

56. Erker S, Stangl R, Stoeglehner G (2017) Resilience in the light of energy crises - part I: a framework to conceptualise regional energy resilience. J Clean Prod. https://doi.org/10.1016/j.jclepro.2017.06.163

57. Bachfischer R (1987) Die ökologische Risikoanalyse. TU München

58. Scholles F (2008) Bewertungsmethoden. Der Relevanzbaum. In: Fürst D, Scholles F (eds) Handbuch Theorien und Methoden der Raum- und Umweltplanung, 3., vollständig überarbeitete Auflage. Rohn, Dortmund

59. Vester F (2012) Die Kunst vernetzt zu denken: Ideen und Werkzeuge für einen neuen Umgang mit Komplexität Ein Bericht an den Club of Rome, 9th edn. dtv Verlagsgesellschaft, München

60. Vester F (1997) Neuland des Denkens. Dtv, München

61. Vester F (1976) Ballungsgebiete in der Krise. Vom Verstehen und Planen menschlicher Lebensräume. Deutscher Taschenbuchverlag, München

62. Lichtenwoehrer P, Erker S, Zach F, Stoeglehner G (2019) Future compatibility of district heating in urban areas- a case study analysis in the context of integrated spatial and energy planning. JESS https://doi.org/10.1186/s13705019-0192-5 
63. Büchele R, Haas R, Hartner M, Hirner R, Hummel M, Kranzl L, Müller A, Ponwieser K (2015) Bewertung des Potenzials für den Einsatz der hocheffizienten KWK und effizinter Fernwärme- und Fernkälteversogung. Endbericht, Vienna

64. EnergieSchweiz (2018) Modul 6: Thermische Netze. Eignung und Realisierung. In: Räumliche Energieplanung Werkzeuge für eine zukunftstaugliche Wärme- und Kälteversorgung. Energie Schweiz für Gemeinden, Sirnach

65. Bridge G, Bouzarovski S, Bradshaw M, Eyre N (2013) Geographies of energy transition: space, place and the low-carbon economy. Energy Policy 53:331340. https://doi.org/10.1016/j.enpol.2012.10.066

66. United Nations (2015) World population prospects: the 2011 revision. United Nations Department of Economic and Social Affairs/Population Division, New York

67. Grübler A, Nakićenović N (1996) Decarbonizing the global energy system. Technol Forecast Soc Change 53:97-110. https://doi.org/10.1016/00401625(96)00049-2

68. Ritchie H, Roser M (2018) Energy production \& changing energy sources. In: OurWorldlnData.org https://ourworldindata.org/energy-production-andchanging-energy-sources

69. Smil V (2016) Energy transitions: global and national perspectives, 2nd edn. Praeger, Santa Barbara

70. McEvedy C, Jones RM (1978) Atlas of World Population History. Puffin, Harmondsworth; New York etc

71. Biraben JN (1980) An essay concerning mankind's demographic evolution. J Hum Evol 9:655-663. https://doi.org/10.1016/0047-2484(80)90099-8

72. United Nations (1999) The world at six billion. Table 1, "world population from" year 0 to stabilization. United Nations, New York

73. Kremer M (1993) Population growth and technological change: one million B.C. to 1990. Q J Econ 108:681-716. https://doi.org/10.2307/2118405

74. FFG (2019) FFG promoting innovation. About the Austrian Research Promotion Agency (FFG). https://www.ffg.at/en/content/about-ffg. Accessed 4 Jan 2019

Ready to submit your research? Choose BMC and benefit from:

- fast, convenient online submission

- thorough peer review by experienced researchers in your field

- rapid publication on acceptance

- support for research data, including large and complex data types

- gold Open Access which fosters wider collaboration and increased citations

- maximum visibility for your research: over $100 \mathrm{M}$ website views per year

At $\mathrm{BMC}$, research is always in progress.

Learn more biomedcentral.com/submissions 